\title{
Aprendizado ativo nas relações internacionais: um estudo empírico sobre o papel do lúdico no processo de aprendizagem
}

\section{Fernanda Cristina Nanci Izidro Gonçalves* Leticia Cordeiro Simões de Moraes Lima**}

\section{RESUMO}

A abundância e a velocidade que informações difusas são disseminadas, características mais marcantes da sociedade contemporânea, exigem uma mudança das formas tradicionais de ensino e aprendizado. Jovens e adultos estão cada vez mais conectados às novas tecnologias que possibilitam acesso imediato a conteúdos cada vez mais palatáveis e diretos, transforman- do a maneira como estes são absorvidos. É latente a necessidade de adaptação da sala de aula à essa nova realidade que precisa posicionar o aluno no centro da construção de seu próprio aprendizado. $\mathrm{O}$ intuito deste artigo é apresentar experiências de Ensino e Aprendizado Ativos, a partir do relato de atividades empíricas realizadas no curso de graduação de Relações Internacionais de uma instituição de ensino privada no Brasil. Busca-se compartilhar os

* Doutora em Ciência Política pelo Instituto de Estudos Sociais e Políticos (IEsp/UerJ). Coordenadora do Núcleo de Estudos Atores e Agendas de Política Externa (NEAAPE), pesquisadora do Observatório Político Sul-Americano (opsa), editora do Boletim NEAAPE, coordenadora e professora do curso de Relações Internacionais no Centro Universitário La Salle-RJ, Niterói - RJ, (Brasil). [fernanda.nanci@lasalle.org.br]; [https://orcid.org/0000-0002-1849-1317].

** Doutoranda em Relaçôes Internacionais pelo PPGRI-UERJ desde agosto de 2016. Mestrado em Relações Internacionais pela UERJ (bolsista CAPES) e graduação em Relações Internacionais pelo Centro Universitário La Salle - RJ (unilasalle-rJ). Coordenadora do Laboratório Universitário de Pesquisa sobre Práticas Ativas de Aprendizado do Centro Universitário La Salle-RJ, Niterói - RJ, (Brasil); [leticia.lima@lasalle.org.br]; [https://orcid.org/0000-00030265-3665]

Recibido: 1 de diciembre de 2019 / Modificado: 29 de enero de 2020 / Aceptado: 28 de febrero de 2020

Para citar este artículo:

Nanci Izidro Gonçalves, F. C. y Cordeiro Simões de Moraes Lima, L. (2020). Aprendizado ativo nas relações internacionais: um estudo empírico sobre o papel do lúdico no processo de aprendizagem. OASIS, 32, pp. $29-47$.

DOI: https://doi.org/10.18601/16577558.n32.04 
resultados obtidos, as estratégias traçadas, as bases pedagógicas utilizadas e as respostas por parte do corpo discente às atividades. Por meio da troca de experiências exitosas na área de ensino, pesquisa e extensão nas Relações Internacionais, entende-se que é possível estimular o diálogo sobre os desafios e as possibilidades de aprendizado ativo para as novas geraçóes de estudantes e analistas internacionais.

Palavras-chave: Ensino, Aprendizado Ativo, Relações Internacionais, Lúdico.

\section{Aprendizaje activo en las relaciones internacionales: un estudio empírico sobre el papel de lo lúdico en el proceso de aprendizaje}

\section{RESUMEN}

La abundancia y velocidad a la que se difunde la información, características llamativas de la sociedad contemporánea, requieren un cambio en las formas tradicionales de enseñanza y aprendizaje. Los jóvenes y los adultos están cada vez más conectados a las nuevas tecnologías que permiten el acceso inmediato a contenidos cada vez más apetecibles y directos, transformando la forma en que se absorbe. Existe una necesidad latente de adaptar el aula a esta nueva realidad que necesita posicionar al estudiante en el centro de la construcción de su propio aprendizaje. El propósito de este artículo es presentar experiencias de enseñanza y aprendizaje activo, basadas en la experiencia de actividades empíricas realizadas en el pregrado de relaciones internacionales de una institución educativa privada en Brasil. Se buscan compartir los resultados obtenidos, las estrategias esbozadas, las bases pedagógicas utilizadas y las respuestas del alumnado a las actividades. A través del intercambio de experiencias exitosas en la enseñanza, la investigación y la extensión en relaciones internacionales, se entiende que es posible estimular el diálogo sobre los desafíos y las posibilidades de aprendizaje activo para las nuevas generaciones de estudiantes y analistas internacionales.

Palabras clave: enseñanza, aprendizaje activo, relaciones internacionales, lúdico

\section{Active learning in international relations: an empirical study on the role of the ludic in the learning process}

\section{ABSTRACT}

The abundance and speed at which diffuse information is disseminated, a highlighted feature of contemporary society, require a change in traditional forms of teaching and learning. Young people and adults are increasingly connected to new technologies that enable immediate access to increasingly palatable and direct content, transforming the way it is absorbed. There is a latent need to adapt the classroom to this new reality that needs to position the student at the center of building their own learning. The purpose of this article is to present Active Teaching and Learning experiences, based on the experience of activities carried out in a BA of International 
Relations of a private educational institution in Brazil. It seeks to share the results obtained, the strategies outlined, the pedagogical bases used and the students responses to these activities. Through the exchange of successful experiences in teaching, research and extension in International Relations, it is understood that it is possible to stimulate dialogue about the challenges and possibilities of active learning for the new generations of students and international analysts.

Keywords: Teaching, Active Learning, International Relations, Ludic

\section{INTRODUÇÃO}

Vivemos em uma sociedade que reproduz um modelo de transmissão de conhecimento, o chamado Paradigma do Ensino, onde uma autoridade que detém conhecimento o transfere de maneira unilateral ao aluno por meio de aulas expositivas e de leitura do material indicado. Espera-se que o aluno internalize o conteúdo através da repetição e não das conexões ou questionamentos que o mesmo faça em relação àquilo que aprende. Há, por outro lado, a proposta para evolução e quebra deste paradigma relacionado à educação massificada: o Paradigma do Aprendizado (Inoue \& Valença, 2017).

Diferente do Paradigma do Ensino, o Paradigma do Aprendizado opera por meio da construção do conhecimento, através de uma interação cooperativa entre discente e docente. O centro deste paradigma está não na assimilação do conhecimento por via da repetição do conteúdo, mas através das conexóes formadas pelos alunos com o contato com aquilo que lhe é apresentado. Como essas conexões podem ser feitas? Tornando o aluno o maior responsável pela construção de seu próprio conhecimento. Para isso é necessário tornar o conhecimento prático e palpável e, acima de tudo, dar significado ao conteúdo que se está aprendendo, levando em consideração o fato de que existem diferentes maneiras de se aprender (Inoue \& Valença, 2017).

A melhor forma de dar significado e, portanto, tornar palpável aquilo que se estuda, é através de uma maior interação entre professores e alunos, o que acaba levando a criação de maneiras para que este estudo seja desenvolvido, guiado pelo professor, mas transformado e moldado pelo aluno, engajado em melhorar cada vez mais sua forma de aprender. Assim, o aluno seria o centro do processo de aprendizagem e o professor um importante coadjuvante. Não se nega a importância do professor, pelo contrário. Contudo, vivemos em tempos em que a informação e o saber não estão concentrados em um indivíduo ou em uma única literatura, mas disseminado, através da tecnologia. Por um lado, isso cria certas dificuldades para o professor, mas por outro uma série de oportunidades para que este possa tornar seu aluno o núcleo nevrálgico da construção de conhecimento dentro e fora de sala de aula.

O professor continua tendo um papel fundamental no processo de aprendizado, mas deve assumir, ao lado de seus alunos, uma nova postura, mais cooperativa, e que possa acelerar, aprofundar e melhorar o processo de aprendizagem dos mesmos. Uma atitude esperada por parte do docente neste novo paradigma de aprendizado pode se dar através da criação 
conjunta de estratégias que auxiliem os alunos a aprender de maneira definitiva assuntos que sejam fundamentais para auxiliar o crescimento como cidadão e como profissional

Deriva deste pensamento a concepção de um Aprendizado Ativo por parte dos alunos, uma vez que este significa envolver os alunos no processo da criação e construção do conhecimento por meio da interação com o conteúdo lecionado, de forma que o assunto tratado ganhe significado e importância para os discentes. A interação é uma das formas mais importantes para o aprendizado e, em sala de aula, deve ser desenvolvida através de estímulos escritos, falados ou interpretados.

A definição de Aprendizado Ativo (ou active-learning em inglês) é "o processo no qual estudantes se engajam em atividades, como leitura, redação, discussóes ou resolução de problemas que promovam a análise, síntese e avaliação do conteúdo estudado" (Crlt, s/ $\mathrm{d}, \mathrm{s} / \mathrm{p})$. Assim, o Aprendizado Ativo é percebido como uma perspectiva para o processo de ensino-aprendizagem que aplica distintas técnicas para o aprendizado em Relações Internacionais (RI).

Nas RI, há três vantagens e contribuições diretas que o Aprendizado Ativo pode fornecer aos alunos: (i) resposta cognitiva positiva, ou seja, quanto mais os alunos se envolvem mais aprendem; (ii) a relação entre conhecimento abstrato e prático facilitada através das atividades interativas em sala de aula; e por fim, (iii) uma retenção de conhecimento ampliada e duradoura devido a atividades com maior envolvimento e prática por parte dos discentes (Lantis et al, 2010).
Contudo, cabe ao professor criar as condiçôes para que sejam estabelecidos senso de propósito e, portanto, as conexões necessárias para que o aprendizado ativo sobre um certo conteúdo aconteça. Esta ação lança as bases para o aumento da autonomia dos alunos sobre o conhecimento que está sendo formado naquele ambiente. Algumas estratégias que auxiliam na criação das conexões necessárias para o processo de aprendizagem seguindo o Paradigma do Aprendizado são: "(i) estudos de casos, (ii) uso de textos alternativos, (iii) simulação e jogos, (iv) uso de tecnologia" (Inoue \& Valença, 2017, p. 5). Vale destacar, contudo, que os objetivos, o planejamento das atividades e a avaliação sobre a eficácia destas, algo que envolve aluno e professor, devem estar sempre em mente para que o processo de aprendizagem seja de fato construído.

Partindo dos significados de Paradigma do Aprendizado e do Aprendizado Ativo o intuito deste artigo é apresentar experiências de Ensino e Aprendizado Ativos, a partir do relato de atividades empíricas realizadas no curso de Relações Internacionais de uma instituição de ensino privada no Brasil. Busca-se compartilhar os resultados obtidos, as estratégias traçadas, as bases pedagógicas utilizadas e as respostas por parte do corpo discente às atividades. A experiência apresentada baseia-se nas atividades implementadas no curso de graduação de Relações Internacionais do Unilasalle-RJ durante a XIII ${ }^{a}$ Semana de Relaçôes Internacionais da instituição, que ocorreu em outubro de 2018, e durante o ano de 2019 no âmbito das iniciativas desenvolvidas pelo 
Laboratório Universitário de Pesquisa sobre Práticas Ativas de Aprendizado (LUPPAA) ${ }^{1}$.

O Unilasalle-RJ é um Centro Universitário privado no Estado do Rio de Janeiro, onde o curso de graduação de Relaçóes Internacionais existe há 15 anos. Coordenação e professores do curso vêm - ao longo dos últimos anos - planejando eventos e práticas acadêmicas voltadas para o aprendizado ativo, trazendo jogos de tabuleiro, simulações, músicas, livros, visitas e viagens técnicas, filmes e séries variadas para fomentar o debate e a prática da política internacional com os alunos de maneira empírica, lúdica e prazerosa.

A metodologia deste artigo é descritiva, baseada no relato do estudo de casos a serem apresentados no decorrer do texto. Através da experimentação prática, buscou-se inserir o ensino lúdico e ativo no âmbito da graduação e colher seus resultados através de questionários semiestruturados aplicados aos participantes das atividades com o intuito de verificar seu nível de aprendizado, satisfação, aderência e participação. Um estudo do tipo descritivo, segundo Gil (2002) não pretende tal qual estudos exploratórios ou explicativos, compreender como ou por que certos eventos acontecem, mas relatar e descrever suas principais características. Desta forma, somado à apresentação das experiências e dos resultados percebidos, apresentam-se os dados referentes à avaliação dos discentes sobre as variadas atividades. Tais dados foram coletados conforme descrito na seção metodológica apresentada a seguir no presente artigo.

\section{METODOLOGIA DE AVALIAÇÃO DAS ATIVIDADES}

Para Lakatos e Marconi (2010) método é um caminho construído que leva a um determinado resultado. Para avaliar as atividades de ensino e aprendizado ativos utilizou-se uma abordagem quali-quanti para a análise dos dados recolhidos durante e após as atividades $\mathrm{e}$ eventos práticos realizados no âmbito do curso de Relações Internacionais da instituição de ensino mencionada.

As atividades práticas realizadas pelo LUPPAA foram pensadas, discutidas e elaboradas pela equipe de professores e alunos do curso de Relaçôes Internacionais. $\mathrm{O}$ objetivo foi promover a participação ativa dos alunos sob coordenação dos professores. Para tanto, tais atividades foram antecedidas por reuniões do grupo de pesquisa e coordenação, envolvendo a elaboração de um roteiro de atividade e sua posterior avaliação. Assim, buscou-se contemplar:

(i) a definição dos objetivos educacionais gerais e de cada atividade; (ii) o planejamento e execuçáo $\mathrm{da}(\mathrm{s})$ atividade(s); (iii) o debriefing específico de cada atividade, a discussão sobre os resultados e reflexão sobre as questóes que emergiram da atividade [...] e (iv) a avaliação final, momento quando o professor e

\footnotetext{
Para mais informações sobre o LUPPAA, ver: <https://www.unilasalle.edu.br/rj/pesquisa/iniciaco-cientifica>. Iniciação Científica> Relações Internacionais > Laboratório Universitário de Pesquisa sobre Práticas Ativas de Aprendizado do Unilasalle-RJ (LUPPAA-LaSalle).
} 
estudantes têm a oportunidade de discutir e avaliar o curso, possibilitando rever estratégias de ensinoaprendizado e adequá-las à novas perspectivas (Inoue \& Valença, 2017, p.5):

Além da importância do roteiro prévio das atividades práticas, integra parte da metodologia de trabalho promover uma avaliação posterior, tanto dos alunos quanto dos professores participantes, das dinâmicas realizadas. Estas avaliações são feitas através do Google Forms, com formato semi-estruturado, ou seja, com perguntas que aceitem respostas abertas e fechadas, com o intuito de acompanhar a evolução e a resposta das partes envolvidas.

O método quantitativo foi escolhido como parte da metodologia por ser um método estabelecedor de comportamentos mensuráveis numericamente e possuir flexibilidade no tratamento das informaçōes, dependendo dos instrumentos utilizados. Os dados obtidos permitiram acompanhar e avaliar os resultados das diferentes práticas de aprendizado vivenciadas. Por outro lado, o método qualitativo estabelece padrões de comportamento, verificados através da interpretação de fatos e dados observáveis, mas não numéricos. Assim, foram realizadas pequenas entrevistas anônimas com alunos, observações participantes pelos pesquisadores da equipe do LUPPAA e análise posterior do conteúdo das atividades (Melo, Monteiro \& Rodrigues, 2013).

A próxima seção apresenta as principais definiçōes conceituais e teóricas que orientam a realização das atividades, eventos e práticas de ensino e aprendizado ativos no curso de Relações Internacionais da instituição de ensino em questão.

\section{DEFINIÇÕES CONCEITUAIS}

O aprendizado ativo tem com princípio teórico a ideia de colocar o aluno como o centro do processo de aprendizado, fazendo com que este se torne uma parte ativa do conhecimento e não apenas um mero reprodutor do conhecimento adquirido através do professor. Para obter sucesso com esse processo, ideias como a de frame shifiting, conceitos de limiar e processo de mesclagem, devem ser muito bem compreendidos pelos professores que buscam adotar esse tipo de metodologia em sala de aula e fora dela.

Colocar os alunos como tomadores de decisão é um frame shifting, uma mudança no ponto de vista, que ajuda os alunos a entenderem melhor algumas posições e ações que, pela percepção de um aluno, seriam de difícil compreensão. Dessa forma, deslocar o papel dos alunos faria com que eles percebessem as dificuldades existentes nas relações de poder, além de notarem que todas as suas ações afetam os demais atores, mesmo que em um nível psicológico. O frame shifiting também ajuda os alunos a perceber como suas ações, como criadores de políticas, podem ter efeitos duradouros (JAFF, 1986).

Ao viver o papel de tomadores de decisão, os alunos seriam capazes de perceber e aplicar conceitos de Ciência Política e RI, criando novos mapas cognitivos e acelerando o processo de aprendizagem. Existem pelo menos dois caminhos para o aprendizado: o processo de informação - mais tradicional -- e o modelo de aprendizado experimental. Coleman (1974) afirma que o processo de aprendizagem é dividido em quatro etapas: (1) receber informação; 
(2) assimilar e entender; (3) inferir aplicaçóes particulares; (4) usar os princípios para agir de acordo. Para o modelo de aprendizagem experimental, o processo é invertido, dando maior foco aos dois últimos estágios - uso dos princípios e inferência de aplicações particulares (Dorn, 1989).

Essa mudança no processo de aprendizagem acontece porque o aluno adquire conhecimento vivendo uma situação e experimentando o conceito. Nesse sentido, o aluno não é uma parte passiva do processo de aprendizagem, ele é uma parte ativa e fundamental dele. $\mathrm{O}$ incentivo ao aprendizado tende a acontecer na terceira e na quarta etapas, tornando o processo de informação menos atraente que o experimental.

O aprendizado ativo é um ótimo método para aprender conceitos de limiar (threshold concepts). Um conceito de limiar é um conceito central que, depois de compreendido, muda a percepção de toda a área do conhecimento. Segundo Meyer e Land (2006), esses conceitos possuem cinco características distintas: transformador, irreversível, integrativo, delimitado e problemático.

A característica transformadora significa que, depois que os alunos aprenderam o conceito, mudam a forma como percebem o assunto. Um exemplo dessa característica é a compreensão do debate marxista, feminista e pós-estruturalista em que uma mudança no ponto de vista pode levar a uma mudança de personalidade, uma "reconstrução da subjetividade" (Meyer \& Land, 2006, p. 7). O fato de o conceito se tornar irreversível se dá pelo seu poder transformador, tornando-o inesquecível ou não passível a um retorno ao estágio antes de ser aprendido. Integrativo significa que, após o conceito de limiar ser entendido, ele expõe relaçóes que antes estavam ocultas para o aluno. Delimitado significa que o conceito está normalmente ligado a uma noção de que todo conhecimento tem uma fronteira, e o conceito de limiar procura expandi-lo (Meyer \& Land, 2006).

Segundo Fauconnier e Turner (2002), existe um caminho neural para o desenvolvimento da aprendizagem chamada mesclagem, em que todo conhecimento é criado a partir de uma mescla entre um conhecimento prévio, os novos conceitos apresentados e um espaço genérico. O resultado dessa mistura é mais do que uma simples soma de todos os fatores. Uma mescla tende a ser imbuída pelo conhecimento anterior (previamente adquirido), os novos conceitos que são apresentados, um conjunto de valores que são comuns a uma sociedade (Espaço Genérico), criando um conjunto de conceitos e conexões entre as entradas anteriores (Mescla).

Um ambiente lúdico de aprendizagem ativa, conforme o que vem sendo construído no curso de RI a partir das atividades que fazem parte deste relato, ajuda o aluno a se sentir à vontade para melhorar suas capacidades de formar vínculos entre os conteúdos apresentados/situações vividas e os conceitos, além de deixá-los mais dispostos a discutir situações que apareceram durante as atividades de aprendizado ativo, mesmo que não tenham domínio de conhecimento sobre elas. Essa atmosfera acaba por promover um processo de aprendizado ainda mais profundo, mesclando situações vivenciadas em atividades de aprendizado ativo e conteúdos previamente adquiridos, gerando 
novos caminhos neurais tornando assim o conhecimento mais duradouro. Além desses benefícios, as atividades de aprendizado ativo fazem com que o aluno consiga desenvolver um pensamento mais crítico e por ser parte ativa da construção do conhecimento, os discentes procuram participar ainda mais, seja de novas atividades ou de atividades mais longas (Lima et al, 2014).

A seção apresentada a seguir oferece um breve histórico sobre o desenvolvimento do campo de ensino das Relações Internacionais no Brasil de modo a demonstrar como as práticas de ensino evoluíram nos últimos anos.

\section{ENSINO EM RELAÇÕES INTERNACIONAIS NO BRASIL}

A área de Relações Internacionais é relativamente nova no Brasil. O primeiro curso de graduação surgiu em 1974 na Universidade de Brasília (UNB) e até então, os estudos da área estavam associados a outros correlatos no campo das Ciências Sociais, como História, Economia, Ciência Política (Vigevani, Thomáz \& Leite, 2014). Com efeito, a proliferação dos cursos de graduação na área se deu durante os anos 1990 e 2000 no bojo das transformaçōes que marcaram as relaçóes internacionais no pós-Guerra Fria e da crescente internacionalização da economia brasileira (Miyamoto, 2003; Lessa, 2005).

Nesse contexto, o interesse por compreender a inserção internacional do Brasil e preparar massa crítica para as oportunidades criadas em organizações internacionais e não-governamentais, na carreira diplomática, em assessorias internacionais do setor público e privado, em comércio exterior e negócios internacionais, na academia e em setores que fazem análises de riscos e de investimentos para empresas estimularam a criação de diversos cursos de graduação em Relações Internacionais em todo o território nacional.

Esses cursos, que possuem bases multidisciplinares e ênfases diversas (como comércio exterior ou estudos diplomáticos, por exemplo), buscavam - e buscam - preparar profissionais com formação competitiva no mercado de trabalho, de forma que pudessem atuar em múltiplas frentes. $\mathrm{Na}$ esteira da expansão da graduação e aproveitando a maior visibilidade da política externa brasileira e o crescente interesse internacional sobre a emergência do Brasil como potência econômica e política, além da atração de investimentos estrangeiros, diversos cursos de pós-graduação em Relações Internacionais, apoiados pelas agências federais e estaduais de fomento ao ensino e à pesquisa, também se proliferaram no país a partir dos anos 2000. Desse modo, o campo das Relações Internacionais começou a se estruturar e a se expandir no Brasil (Carvalho, Gonçalves \& Araújo, 2017).

Este destaque para o internacional no país tornou necessário que o próprio ensino de Relações Internacionais se tornasse alvo de investigação, uma vez que é imprescindível compreender como os futuros 'internacionalistas' estão sendo ensinados e de que maneira este aprendizado está sendo absorvido. No Brasil, a criação do subcampo sobre Ensino e Pesquisa da Associação Brasileira de Relações Internacionais (ABRI) trouxe bases sólidas para as produções acadêmicas neste campo, mas também para as atividades práticas e para as 
trocas de experiências entre docentes, pesquisadores e mais recentemente discentes (Carvalho, Gonçalves \& Araújo, 2017).

No que se refere às estratégias e instrumentos de aprendizado ativo, vale destacar que ele não é um tema recente na academia, mas este tipo de atividade passa a ganhar destaque e força no campo das Relações Internacionais nas últimas duas décadas. As grandes conferências internacionais sobre Política Internacional, como os encontros anuais da International Studies Association (ISA) e da American Political Science Association (APSA), possuem áreas exclusivas para o debate do processo de ensino-aprendizado na área e representam um dos principais mecanismos para a popularização de métodos em prol do aprendizado ativo. Esta divulgação, debate e troca de experiências normalmente é realizada em painéis e conferências, além de reuniōes e lançamentos de livros voltados para estas temáticas que vão do Ensino Ativo ao Aprendizado Ativo, muitas vezes com o oferecimento de bolsas para acadêmicos que possuam experiências exitosas para compartilhar.

Desde 2002, por exemplo, a IsA possui uma seção independente com publicação própria sobre Ensino Ativo a Active Learning in International Affairs Section (ALIAS), que marca o campo do ensino e aprendizado ativo nas Relações Internacionais, uma vez que materializa a reunião de acadêmicos interessados nesta área de pesquisa e que enxergam a importância deste tipo de posicionamento para o aprendizado das atuais e futuras gerações de profissionais $\mathrm{da}$ área. A partir desta iniciativa, a APSA lançou em 2004 uma conferência unicamente voltada para ensino e Pesquisa, e a ISA fez o mesmo a partir de 2017, o que permitiu o aumento do debate e da utilização do aprendizado ativo nas áreas de RI e de Ciência Política nos euA e em outros países, o que inclui o Brasil, ainda de maneira tímida (INOUE; VALENÇA, 2017).

Com um campo sobre aprendizado ativo se consolidando como uma área nas Relações Internacionais nas últimas décadas, houve espaço e interesse para que uma literatura especializada também começasse a ser desenvolvida, que versa não só sobre técnicas e exercícios de aprendizado ativo na sala de aula, mas sobre experiências já desenvolvidas e os objetivos traçados e resultados alcançados para cada atividade desenvolvida. Muitas são as formas de desenvolver o aprendizado ativo no campo das Relações Internacionais com bons resultados comprovados. Algumas atividades estão sendo utilizadas há mais tempo, e, portanto, acabaram tornando-se mais usuais, mas todo tipo de interação entre discentes e docentes que permitam que aqueles construam seu conhecimento de forma ativa, pode ser compreendido dentro das metodologias ativas.

A instituição de ensino, objeto deste artigo, tem como um de seus objetivos institucionais a utilização de metodologias ativas para preparar alunos engajados com sua formação e com um diferencial prático para o mercado de trabalho. Dentro desta atuação diferenciada, podemos destacar ações de aprendizado ativo no Centro Universitário, dando destaque às atividades que envolvam o lúdico e o prático.

Na XIII a Semana de Relações Internacionais do Unilasalle-RJ, que ocorreu em outubro de 2018, coordenação e professores do curso planejaram a programação do evento para o aprendizado ativo, trazendo jogos de tabuleiro, 
simulações, filmes de super-herói e séries de TV para fomentar o debate e a prática da política internacional com os alunos de maneira prazerosa. O engajamento, participação e feedback foram extremamente positivos e os pedidos para que este tipo de atividade se tornasse uma constante no curso deu origem ao Laboratório Universitário de Pesquisa sobre Práticas Ativas de Aprendizado (LUPPAa) em 2019.

O luppaA é um espaço destinado à cooperação discente-docente, concepção e realização de atividades práticas que prezam pela aplicação ativa e lúdica do conteúdo aprendido nas diversas disciplinas do curso. Também é um laboratório dedicado à pesquisa das bases pedagógicas para pensar e avaliar as técnicas de ensino-aprendizado ativos, as principais referências nessas áreas e as práticas exitosas, existentes em outras instituiçôes de ensino. Ademais, funciona como um centro de análise de dados das diversas iniciativas de aprendizado ativo realizadas na Instituição.

Tendo em vista as práticas implementadas, apresentam-se a seguir as atividades realizadas entre 2018 e 2019 no curso de graduação, discutindo seus resultados.

\section{TEORIA E PRÁTICA NAS RELAÇõES INTERNACIONAIS: RELATOS DE UMA EXPERIÊNCIA DE APRENDIZADO ATIVO}

No ano de 2018, o curso de Relaçóes Internacionais do Centro Universitário Unilasalle-RJ, organizou seu evento acadêmico anual sob a temática "Teoria e Prática nas Relações Internacionais". O evento foi realizado entre os dias 22 e 28 de outubro e apostou no universo do entretenimento para envolver os graduandos, apresentando discussões atuais da área, por meio de um tom lúdico e divertido para as atividades realizadas ao longo da semana ${ }^{2}$.

A primeira atividade do evento envolveu a exibição de um filme blockbuster aliado ao debate das professoras das disciplinas História da África e de Teoria das Relações Internacionais. A sessão cinema apresentou "Pantera Negra", filme vencedor de três Oscar e indicado à categoria de Melhor Filme. O objetivo desta atividade foi discutir conceitos dos estudos africanos, das teorias pós-coloniais e feministas a partir de elementos da cultura pop, como o filme de super-herói, fomentando um debate crítico e atual. No que tange à temática dos estudos africanos, foram elencados conceitos próprios do estudo do continente, falou-se acerca da reprodução de estereótipos e defendeu-se a importância do destaque dado a temas, em geral esquecidos pela grande mídia, no filme.

Por outro lado, foi possível trabalhar teorias mais recentes associadas às Relaçóes Internacionais como o Feminismo e o Pós-Colonialismo. A intenção dos organizadores com esta atividade foi expor discentes do curso às temáticas muitas vezes consideradas marginais nos estudos das Relações Internacionais por meio de elementos que estão em seus momentos de lazer, como os filmes de super-heróis,

\footnotetext{
2 Para mais informações sobre a programação da Semana e atividades, ver matéria no site oficial da instituição sobre o evento: <https://www.unilasalle.edu.br/rj/noticias/13-semana-de-relacoes-internacionais>.
} 
que têm grande apelo entre os alunos. Os discentes, por sua vez, participaram ativamente com comentários e perguntas ao longo da discussão que ocorreu logo após a apresentação de "Pantera Negra".

A segunda atividade foi dedicada ao active learning e à conjugação da teoria e da prática nas Relações Internacionais por meio de jogos de tabuleiro, de cartas e de simulações fictícias. Com a utilização simultânea das três salas do Espaço Conecta da instituição - formado por três espaços inovadores que permitem uso de tecnologia e trabalhos em conjunto - os discentes puderam escolher entre diferentes atividades que os estimulavam a trabalhar com conhecimentos aplicados aos estudos das disciplinas que compóem a grade do curso de Relações Internacionais. Nesse sentido, muitos estudantes puderam colocar em prática conceitos como equilíbrio de poder, negociação, cooperação e estratégia.

$\mathrm{Na}$ primeira sala do Espaço Conecta os alunos puderam jogar jogos de cartas como Soberano e Coup, que trabalhavam temáticas como assimetria de informaçóes, controle de recursos, alianças políticas e dilemas de cooperação. Simultaneamente, na segunda sala, os alunos experimentaram o jogo de tabuleiro Pacific Armada, que coloca no tabuleiro uma situação real: a disputa entre EUA e Japão no Oceano Pacífico durante a Segunda Guerra Mundial. Antes de jogarem, os alunos ouviram uma breve palestra sobre os conflitos no Pacífico associados aos dois países que protagonizavam a disputa.

Utilizando uma terceira sala tecnológica, os discentes participaram de uma simulação da Organização das Nações Unidas, onde tinham que resolver uma situação problema apresentada por meio de um vídeo elaborado justamente para a ocasião: com a chegada de alienígenas de um planeta distante à Terra, em busca de recursos naturais, quais estratégias e decisões os países iriam adotar? Cooperar com os alienígenas ou responder com o uso da força? Cada grupo representou um país diferente e um grupo ficou responsável por representar os interesses dos alienígenas na Terra.

O conjunto destas atividades foi muito elogiado pelos alunos, que sentiram que estavam ativamente construindo o conhecimento ao qual são expostos em sala de aula, identificando situações e conceitos relativos ao estudo da Geopolítica, da Cooperação Internacional e das Organizações Internacionais ao terem que lidar com a situação problema.

Outra atividade desenvolvida ao longo do evento foi a Mostra de Iniciação Científica, onde foram expostos os banners apresentados pelos estudantes do curso de Relações Internacionais no Encontro da Associação Brasileira de Relações Internacionais (ABRI) de 2018, a revista organizada pelas estudantes do $2^{\circ}$ período no âmbito do projeto da disciplina de Atividade Integradora e o banner apresentado por estudantes no Congresso Acadêmico de Defesa Nacional, organizado pelo Ministério da Defesa, em 2018. A Mostra de Iniciação Científica se insere no esforço dos professores e coordenação de curso de estimular a formação dos estudantes, tornando-os mais autônomos na pesquisa e capazes de buscar conhecimentos e aplicá-los. Nesse sentido, os alunos são estimulados nestas atividades extracurriculares a buscarem respostas a problemas de pesquisa, estudarem metodologias, aprofundarem 
conhecimento sobre diversos temas, não se tornando apenas depositários de informações, mas construtores do próprio conhecimento.

Outra atividade que envolveu o tema do aprendizado ativo foi uma mesa de discussão sobre "Experiências de Active Learning em RI", que envolveu professores convidados que compartilharam seus relatos e explicaram como podemos tornar os conteúdos estudados na área mais aplicáveis para os estudantes a partir de práticas como story telling, discussão de filmes e séries, discussão de livros e sala de aula invertida.

O evento foi encerrado com uma mesa sobre cultura pop, discutindo a série de sucesso mundial da нво, Game of Thrones (GOT), à luz de teorias e abordagens do campo de estudos. Foi aplicado o estudo dos líderes - da área de Análise de Política Externa - aos personagens de GOT, identificando os traços de liderança dos protagonistas. A série também foi discutida a partir do olhar da Economia Política Internacional e das lentes de gênero. Muitas contribuições surgiram no debate com os estudantes, que acompanham o seriado, leem os livros e conseguem identificar diversas conexões entre conceitos e teorias e o mundo fictício apresentado em Westeros.

Em resposta ao questionário aplicado pela Coordenação de curso aos 107 participantes do evento para avaliação das atividades, 97,4\% dos estudantes avaliaram as atividades práticas como divertidas; $100 \%$ respondeu que participaria novamente; 94,6\% respondeu que aplicou conceitos aprendidos nas disciplinas nas atividades realizadas e 100\% afirmou gostar de métodos ativos de ensino. Estas respostas demonstraram que o aprendizado ativo é não apenas uma demanda por parte dos alunos, mas uma oportunidade para que discentes se interessem mais pela sua formação e passem a ter mais prazer na construção do conhecimento. Desse modo, o evento demonstrou que discutir teoria e prática no campo é fundamental e que o processo de ensino-aprendizagem é estimulado e mais prazeroso com a conjugação das duas dimensóes, gerando a ideia de criar um laboratório de pesquisa dedicado a implementar mais iniciativas que envolvessem aprendizado ativo e mais pesquisa que fundamentasse teoricamente as ações.

Nesse sentido, em março de 2019 foi dado início ao trabalho do LUPPAA na instituição. O primeiro desafio foi compor o grupo com professores e discentes que possuíssem conhecimentos diversos e estivessem interessados em pesquisar mais sobre o tema. Assim, o grupo foi formado por 12 pesquisadores: 7 alunos, 4 professoras (de áreas de conhecimento distintas) e 2 pesquisadores associados (egressos do curso). Este grupo ficou responsável por elaborar um cronograma de atividades que abrangesse atividades de ensino e aprendizado ativo mais diversas possíveis.

A partir da definição das iniciativas que seriam implementadas, o grupo envolveu-se na pesquisa das bases pedagógicas, orientadas pelo Paradigma do Aprendizado mencionado neste artigo, e na produção de roteiros e questionários semiestruturados para avaliação das atividades. A primeira iniciativa do grupo foi realizada como comemoração ao dia 08 de março, dia internacional da mulher, e se destinou a apresentar e discutir o documentário "Exteriores - Mulheres Brasileiras na Diplomacia”. Antes da apresentação do documentário, 
os estudantes responderam a um questionário com algumas questões que envolviam dados sobre a participação das mulheres na política no Brasil e no mundo, na Chancelaria, na sociedade e que tratavam dos principais desafios que as mulheres enfrentavam em sua luta por igualdade de condiçóes.

Após a exibição do documentário e debate mediado pelas professoras do curso com os presentes, os resultados dos questionários preenchidos pelos estudantes foram apresentados e uma nova discussão foi gerada a partir da apresentação destes dados. Nesse sentido, os discentes foram envolvidos com a temática desde antes da apresentação do documentário, não sendo meros espectadores, mas observadores atentos à realidade apresentada, que está entrelaçada com a realidade da sociedade brasileira e internacional num espectro mais amplo.

Outra iniciativa coordenada pelo LUPPAA foram os I e II Paintball de Geopolítica e Segurança Internacional. Como parte das disciplinas estudadas no curso, os alunos foram convidados a participarem de uma simulação no campo, como o Paintball. Divididos em dois grupos, os alunos tiveram uma verdadeira experiência de lidar com situação de crise e buscaram decifrar várias charadas que relacionavam as situações vividas no Paintball com exemplos reais da política internacional, inclusive trabalhados nas aulas de Geopolítica ao longo do semestre. Ao final da experiência, responderam um questionário relacionando a atividade prática com os conhecimentos apreendidos em sala de aula, destacando a aplicação de conceitos como: estratégias de guerra, geoestratégia, dilema de segurança, cooperação, teoria ofensiva-defensiva, ganhos relativos e absolutos, guerra assimétrica, assimetria de poder, entre outros.

O Luppa também organizou um evento dedicado à discussão de músicas e suas relações com acontecimentos da política internacional. O grupo organizou uma lista de reprodução com canções nacionais e internacionais no Spotify e a partir da leitura das letras e audição das músicas, foi discutido como as diferentes canções se conectavam com os momentos vividos pela sociedade brasileira e internacional. Foram trabalhadas canções da Música Popular Brasileira, mas também do pop e do rock internacionais, destacando-se algumas com bastante impacto para as Relações Internacionais. Os professores convidados que conduziram parcialmente o evento trouxeram músicas como 'Soy loco por ti América' de Caetano Veloso, onde pode-se pensar na relação do Brasil com os demais países da América Latina e do Norte e como tais relações são quase sempre assimétricas. Outra música trazida pelos professores do curso foi 'El derecho de vivir em paz' de Victor Jara e a partir dela foi debatida a ditadura no Chile e na América Latina e a recente utilização da canção nos protestos do final de 2019 naquele país.

Contudo, não só os professores apontaram músicas para serem debatidas em seus contextos históricos e, claro dentro das diferentes interpretações possíveis. Os alunos que participaram da atividade sugeriram uma série de músicas interessantes como 'This is America' de Childish Gambino', 'Sunday Bloody Sunday' do U2, 'Cálice' de Chico Buarque, 'Imagine' de John Lennon, 'Fortunate Son' do Creedence, entre tantas outras. Desta forma, foi possível debater questões muito atuais e 
relevantes para as Relaçóes Internacionais de forma interessante e prazerosa. Os discentes, por sua vez, participaram ativamente comentando sobre Guerras - em especial a do Vietnã, racismo e seu reflexo na política internacional, nacionalismos, regimes autoritários, movimentos populares e até mesmo teorias de Relações Internacionais como o pós-colonialismo.

O grupo também ajudou a organizar um evento sobre Relações Internacionais, Literatura e Migração no âmbito do curso. Nesta iniciativa, os estudantes leram alguns contos do livro "Intérprete de Males", de Jhumpa Lahiri, discutindo a realidade dos migrantes apresentada nos contos a partir de uma perspectiva que contemplasse a contextualização da migração apresentada no livro, que envolve a independência da Índia, do Paquistão e de Bangladesh e a migração para os Estados Unidos. Desse modo, se tornou possível associar contos de ficção com o fenômeno migratório que continua tendo suas repercussões em distintas regióes, trabalhando com os estudantes a migração não apenas do ponto de vista teórico e conceitual, mas sob a lente dos personagens que vivenciam a experiência, a partir do relato de sentimentos e dificuldades de inserção em contextos sociais. Essa discussão é de particular relevância no momento atual, em que o Brasil se tornou destino de muitos migrantes venezuelanos e sírios.

O Luppa também repetiu a aplicação de jogos de tabuleiro e cartas em 2019, trazendo novamente jogos que foram sucesso na primeira edição, e materiais novos. $\mathrm{O}$ jogo Coup, um dos preferidos da primeira edição, possibilitou sua associação com as alianças ad hoc nos períodos de guerra. Outro jogo de cartas foi o
Honshu, que se passa na ilha central do Japão durante o período medieval e permite que os alunos montem suas próprias vilas, precisando conectar elementos da Geopolítica e seus recursos estratégicos, com a política ambiental e a importante ideia de dependência da trajetória. Outro jogo apresentado foi o Twilight Struggle que leva os jogadores para o período da Guerra Fria, interpretando o papel dos Estados Unidos ou da Uniāo Soviética, precisando evitar uma guerra nuclear e vivenciando as diferentes fases, políticas e acontecimentos daquele período. Por fim, um dos jogos mais disputados foi o Imperial 2030, que mesclou conceitos de War e Banco Imobiliário em níveis mais elevados, uma vez que os jogadores são investidores e não países, mas podem controlá-los.

Adaptando um pouco as regras originais dos jogos, foi aplicada em algumas rodadas, a estratégia da tomada de decisão, onde não só um jogador deveria representar suas peças e movimentaçóes pelo tabuleiro, mas um grupo de dois ou mais alunos precisavam debater, brevemente entre si sobre qual rumo tomar. A atividade, que foi apresentada mais de uma vez no ano de 2019, foi uma das que mais agradou os discentes que puderam perceber e aplicar conceitos dos mais variados como anarquia internacional, assimetria de informações, dilema de segurança, heartland, auto-ajuda, fundamentos de comércio exterior e geopolítica, dissuasão e outros.

Além destas ações, o grupo também ajudou a coordenação de curso a organizar uma série de visitas técnicas. Ao longo de 2019 os estudantes conheceram a área internacional da Prefeitura da Cidade do Rio de Janeiro, o 
Palácio Itamaraty (antiga sede da Chancelaria brasileira), visitaram a Escola de Comando Maior do Exército (ECEME), a Escola Naval e a Casa FIRJAn (da Federação de Indústrias do Estado do Rio). Também realizaram uma viagem de estudos a Brasília, capital brasileira, onde conheceram as principais instituições políticas nacionais, e uma viagem à cidade de Montevidéu no Uruguai, com o objetivo de conhecer in loco as principais instituições regionais. Todas estas experiências contribuíram - no plano prático - para apresentar aos estudantes um pouco da realidade dos analistas internacionais, diplomatas, militares e funcionários civis que trabalham em organismos internacionais, apresentando oportunidades interessantes de trabalho no campo.

Ainda em 2019, dentro da disciplina de Atividade Integradora do Curso de Relações Internacionais, foi desenvolvida a primeira simulação das Nações Unidas no curso de Relações Internacionais da instituição para o Ensino Médio, que foi batizada de SimunLasalle. Durante um semestre, discentes de duas turmas prepararam a simulação para alunos do Colégio Abel, mesma rede do Unilasalle-RJ: desde os convites aos alunos, passando pelo coffee break, logo, nome da Simulação (escolhida por meio de votação) e papelaria do evento. Tudo relacionado à parte acadêmica da atividade também foi pensado e executado pelos alunos. Neste sentido, foi desenvolvido de forma conjunta, um manual da Simulação, os relatórios enviados aos participantes, a escolha da temática a ser tratada e a moderação, a organização e a participação no dia do evento. A temática escolhida foi bastante atual: os Obje- tivos de Desenvolvimento Sustentável da ONU e suas implicações para os países. Os resultados foram muito positivos, além de ter gerado um sentimento de satisfação dos alunos por terem desenvolvido o evento de maneira autônoma. Como resultado, esta simulação será repetida no próximo ano no curso.

Ao final de todas as atividades descritas, seguindo a metodologia apresentada na seção 2 deste artigo, os alunos participantes responderam a um questionário onde expuseram sua percepção sobre as práticas, os principais conceitos de RI que conseguiram aplicar, o quanto as atividades alcançaram suas expectativas e foram dinâmicas. Os resultados das avaliações de todas estas atividades compreendem uma amostra de 127 respondentes e são apresentados a seguir.

\section{Gráfico 1 - Percepção Geral sobre as atividades de Active Learning}

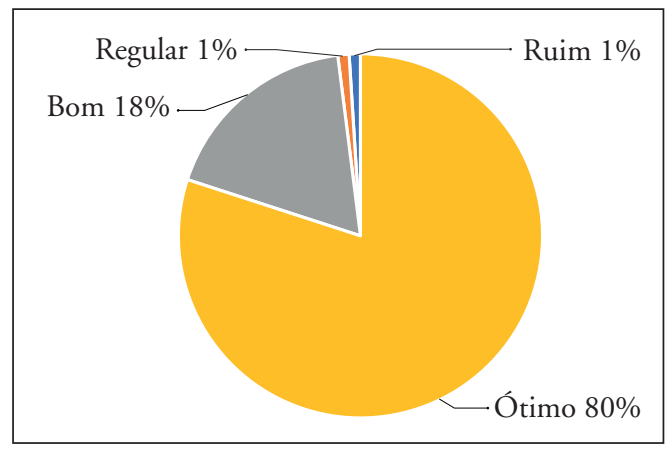

Fonte: Elaboração própria a partir dos questionários

Como se pode notar, 98\% dos estudantes avaliou positivamente as atividades de apren- 
dizado ativo implementadas no curso, com $80 \%$ das avaliações sendo ótimo e $18 \%$ bom.

\section{Gráfico 2 - Nível de Dinamicidade das atividades de Active Learning}

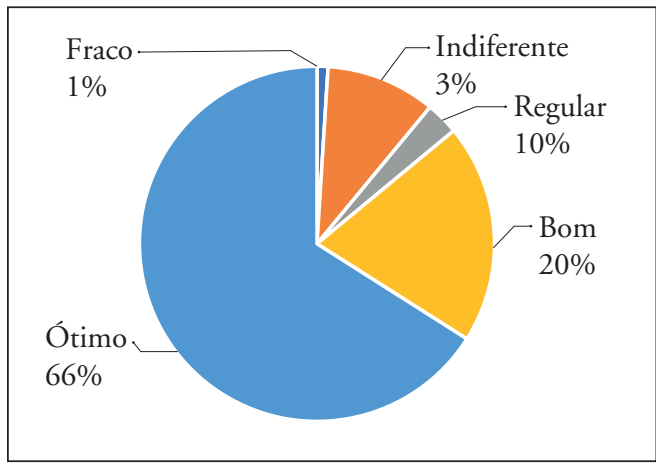

Fonte: Elaboração própria a partir dos questionários

Do mesmo modo, a avaliação sobre o quão foram dinâmicas as atividades foi bastante positiva: $66 \%$ do alunado considerou ótimo e $20 \%$ bom. Apenas $10 \%$ considerou as atividades regulares e $3 \%$ se mostrou indiferente a este aspecto.

\section{Gráfico 3 - Alcance de Expectativas das atividades de Active Learning}

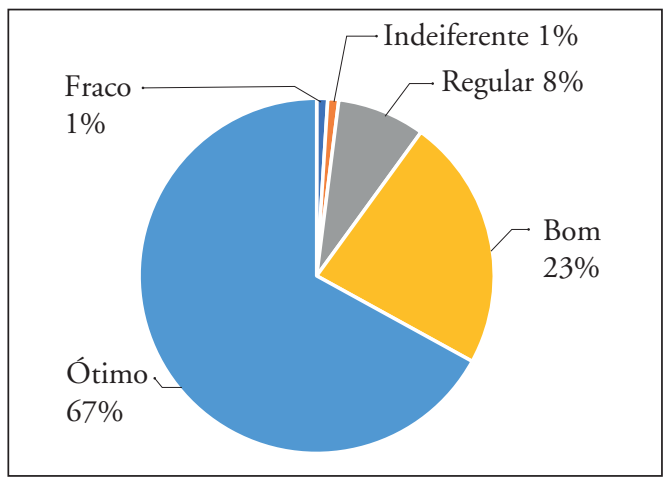

Fonte: Elaboração própria a partir dos questionários
Com relação às expectativas, $67 \%$ dos alunos considerou que as expectativas foram alcançadas no nível ótimo, enquanto 23\% no nível bom. Apenas $9 \%$ do corpo discente não teve suas expectativas alcançadas.

\section{Gráfico 4 - Aplicação de Conceitos nas atividades de Active Learning}

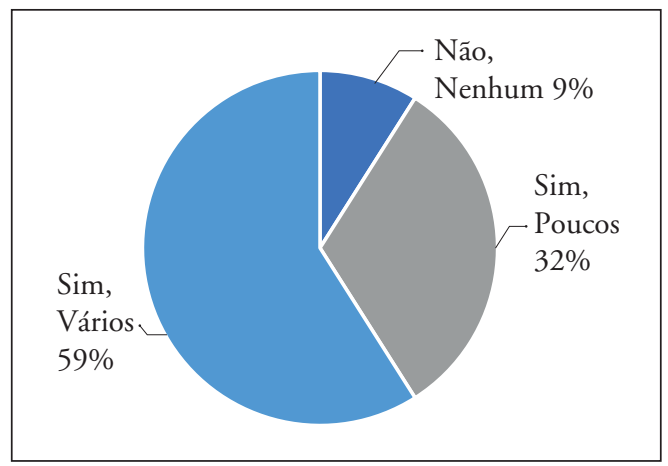

Fonte: Elaboração própria a partir dos questionários

Com relação à aplicação de conceitos estudados nas disciplinas durante a realização das diversas atividades, 91\% dos alunos considerou possível aplicar os conteúdos estudados às dinâmicas. Apenas 9\% dos discentes considerou que não foi possível associar as atividades aos conteúdos estudados.

A figura a seguir apresenta a nuvem de palavras produzida a partir da avaliação dos estudantes sobre os principais termos e conceitos que ao longo da realização destas diversas atividades eles conseguiram aplicar e associar às mais variadas disciplinas.

Como é possível notar, a experiência adotada no curso em prol da promoção da adoção do Paradigma do Aprendizado em concomitância com o Paradigma Tradicional do 
Figura 1 - Nuvem de palavras com os principais conceitos/conteúdos identificados pelos estudantes nas atividades de Active Learning

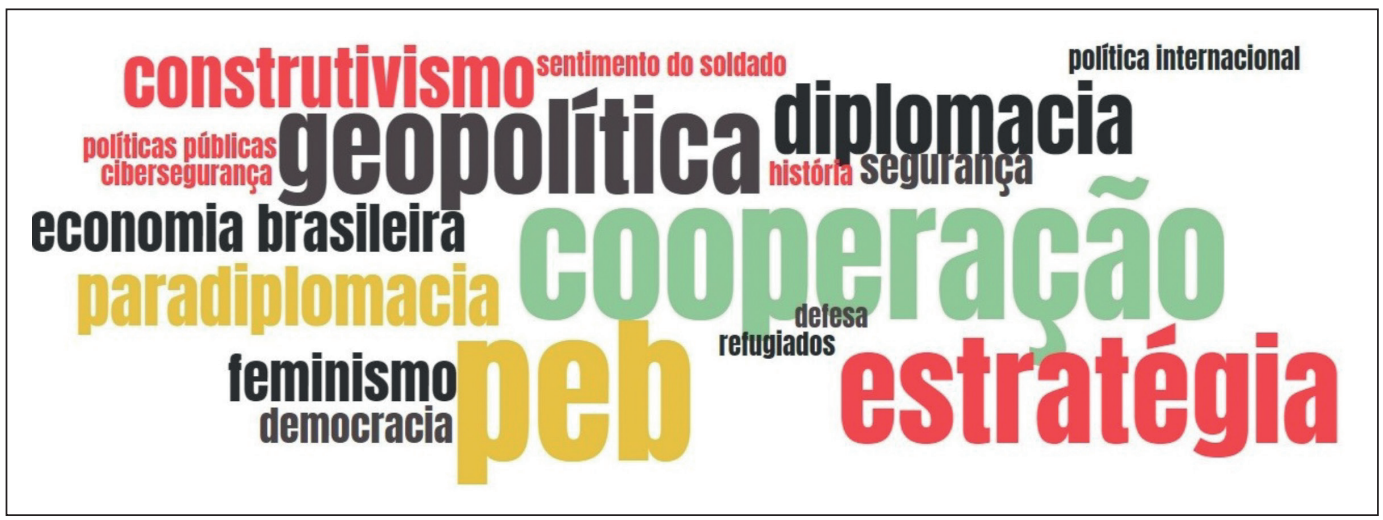

Fonte: Elaboração própria a partir dos questionários

Ensino produziu bons resultados. Os discentes identificaram positivamente as transformações no modelo de ensino-aprendizagem adotados no curso e, inclusive, começaram a demandar mais práticas ativas nas disciplinas.

Como identifica Jaff (1986), o aprendizado ativo muda a percepção da área do conhecimento e é transformador, irreversível e integrativo. A experiência no curso de Relações Internacionais do Unilasalle-RJ tem confirmado exatamente isso: a possibilidade de transformar a forma como os alunos aprendem e os professores ensinam; a maior capacidade de colaboração entre discentes e docentes durante a preparação e execução das atividades e suas avaliaçôes; a possibilidade de integrar diferentes conhecimentos e aplicar conteúdos de diferentes disciplinas em uma mesma atividade de aprendizado ativo; e a irreversibilidade deste caminho, uma vez que a construção do conhecimento de forma colaborativa desloca a transmissão do conhecimento de forma uni- lateral para uma nova experiência colaborativa que torna o aprendizado e o ensino mais dinâmicos e adaptados à nova realidade social.

\section{CONSIDERAÇÕES FINAIS}

[...] tanto ensinar quanto aprender são desafios cada vez maiores e que devem ser pensados e reformulados para evitar momentos monótonos em sala de aula e para superar a falta de interesse dos alunos por certos temas ou disciplinas. Assim, entende-se que é possível superar métodos ultrapassados e que estão muito longe da realidade dos alunos. Especialmente em razão do enorme fluxo de informaçóes e das mudanças sociais e comportamentais, mais do que nun$\mathrm{ca}$, é preciso refletir e trocar experiências exitosas que podem ser difundidas e até mesmo aperfeiçoadas por outras instituiçóes de ensino e em outros campos de estudo (Carvalho, Gonçalves \& Araújo, 2017, p.160)

A abundância e a velocidade que informações difusas são disseminadas, características mais 
marcantes da sociedade contemporânea, exigem uma mudança das formas tradicionais de ensino e aprendizado. É latente a necessidade de adaptação da sala de aula à essa nova realidade que precisa posicionar o aluno no centro da construção de seu próprio aprendizado. Como relatado neste artigo, é possível e viável que professores de Relações Internacionais se insiram neste esforço de quebrar o Paradigma do Ensino e investir no Paradigma do Aprendizado, investindo em formas ativas de ensino-aprendizagem como demonstramos por meio da experiência do Centro Universitário apresentado.

Tão importante quanto estimular os discentes a se engajarem em atividades cada vez mais ativas e que permitam que os próprios construam seu aprendizado e apliquem aquilo que aprendem de maneira teórica na prática é estimular os docentes a propor esse tipo de atividades e também incorporá-las em suas aulas ou em eventos de extensão. Dentro dos seminários docentes do Unilasalle-RJ as técnicas de aprendizado ativo já estão sendo apresentadas através de oficinas semestrais que valorizam este tipo de técnica e sugerem formas de aplicá-las. Também nos seminários docentes, prática da instituição, são apresentadas aos professores e valorizadas as iniciativas inovadoras que servem de exemplo e inspiração para novas maneiras de ensinar e aprender. Especificamente no curso de Relaçōes Internacionais da instituição, o corpo docente do departamento já foi convidado a participar ou a propor atividades lúdicas e ativas para os discentes do curso. O engajamento vem sendo positivo e crescente.
Espera-se, por meio deste relato e do compartilhamento das atividades do curso e das contribuições do LUPPA, contribuir cada vez mais com o conhecimento na área de Ensino, Pesquisa e Extensão em Relações Internacionais e dividir com a comunidade acadêmica práticas e experiências exitosas que tiveram resultado positivo com os docentes e os estudantes na instituição.

\section{REFERÊNCIAS}

Carvalho, P.; Gonçalves, F. \& Araújo, R. (2017). Prática de pesquisa e ensino de relaçóes internacionais: relatos sobre experiência de pesquisa em comércio internacional. Meridiano 47 - Journal of Global Studies, n. 18.

Coleman, J. S. (1978). Information Processing and Experimental Processing: teo modes of learning. In: Stadsklev, R. (Ed.). The Handbook of Simulation Gaming in Social Education, Part 1. Institute of Higher Education Research and Services, University of Alabama.

Crlt - Center For Research On Learning And Teaching. (s.f.). Active Learning. Disponível em <http:// www.crlt.umich.edu/active_learning_introduction>. Acesso em: 15 fev. 2019. Sem Data.

Dorn, D. (1989). Simulation Games: One More Tool on the Pedagogical Shelf. Teaching Sociology, vol. 17 , n. 1 .

Gil, A. C. (2002). Como elaborar projetos de pesquisa. 4a ed. São Paulo: Editora Atlas.

Fauconnier, G. \& Turner, M. (2002). The Way We Think: conceptual blending and the mind's hidden complexities. Basic Books. 
Inoue, C. \& Valença, M. (2017). Contribuiçôes do Aprendizado Ativo ao Estudo das Relações Internacionais nas universidades brasileiras. Meridiano 47 - Journal of Global Studies n. 18.

Jaff, J. (1986). Frame-Shifting: An Empowering Methodology For Teaching and Learning Legal Reasoning. Journal of Legal Education, vol. 36.

Lakatos, E. \& Marconi, M. (2010). Fundamentos de metodologia cientifica: Técnicas de pesquisa. 7a ed. São Paulo: Editora Atlas.

Lantis, J.; Kille, K. J.; Krain, M. (2010). The State of the Active Teaching and Learning Literature. In: Denemark, Robert A. (ed). The International Studies Encyclopedia. Malden: Wiley-Blackwell.

Lessa, A. C. (2005). Instituiçóes, atores e dinâmicas do ensino e da pesquisa em Relaçóes Internacionais no Brasil: o diálogo entre a história, a ciência política e os novos paradigmas de interpretação (dos anos 90 aos nossos dias). Revista Brasileira de Politica Internacional, vol.48, n.2, p.169-184.

Lima, M.; Simões, L.; Gonçalves, R. \& Araujo, P. (2014). Roll the Dice! An Empirical Experience Toward the Use of Board Games in IR Classrooms. Paper apresentado na International Studies Association 2014 Annual Convention Toronto, Canada, 2014
Melo, M.; Monteiro, L. \& Rodrigues, D. (2013). Paradigmas quantitativo e qualitativo no cotidiano da investigação. Interfaces Cientificas - Humanas e Sociais. Aracaju vol. 2, n. 1.

Meyer, J. \& Land, R. (2006). Overcoming Barriers to Student Understanding: threshold concepts and troublesome knowledge. Routledge.

Miyamoto, Shiguenoli. (2003). O Ensino das Relaçôes Internacionais no Brasil: problemas e perspectivas. Revista de Sociologia e Política, vol.20, p. 103-114.

Unilasalle-RJ. (2018). XIII Semana de Relações Internacionais. Website Institucional do Unilasalle do Rio de Janeiro. Disponível em:_https://www.unilasalle.edu.br/rj/noticias/13-semana-de-relacoesinternacionais Acesso em 30/11/2019

Unilasalle-RJ. (s.f.). Iniciação Científica no Curso de Relaçôes Internacionais: LUPPAA-LaSalle. Website Institucional do Unilasalle do Rio de Janeiro. Disponível em https://www.unilasalle.edu. $\mathrm{br} / \mathrm{rj} /$ pesquisa/iniciacao-cientifica Acesso em 30/11/2019. Sem data.

Vigevani, T.; Thomáz, L. \& Leite L. (2014). As Relaçóes Internacionais no Brasil: notas sobre o início de sua institucionalização. Inter-Relações, ano 14, n. 40 , p. $5-11$. 